\title{
STUDY OF NON-INVASIVE INSTRUMENTS FOR THE MEASUREMENT OF PULSED X-RAY HIGH VOLTAGE TUBE
}

\author{
Mohamed Agazar ${ }^{1, *}$, Denis Perrillat ${ }^{2}$, Hanane Saadeddine ${ }^{1}$, Christophe Robert $^{2}$, Laurence Casteignau ${ }^{2}$, Dominique \\ Fortune $^{1}$ \\ ${ }^{1}$ LNE, Laboratoire National de métrologie et D’Essais, 29 Av Roger Hennequin 78197 Trappes, France. \\ ${ }^{2}$ GEMS, General Electric Medical Systems, 283 Rue de la Minière, 78530 Buc, France
}

\begin{abstract}
Non-invasive instruments (kVp meters) are widely used in radiology with diagnostic and guidance systems. Placed in the x-ray beam, they combine detectors and filters, to determine X-ray tube voltage and exposure time, which are the most important quantities in radiology and diagnostic quality control. Calibration of these instruments were limited by reference bench capabilities. General Electric Medical System France and LNE (The national metrology institute in France) have developed a reference bench for the characterization of $\mathrm{kVp}$ meters. The set up includes a fast high voltage generator associated with its internal measuring systems and an X-ray tube. The measurements are compared with an invasive reference standard. The set-up is installed in a Faraday cage, precautions have been taken in order to carry out accurate measurements and special adaptations have been made to avoid stray capacitances, which affect the dynamic performance of the generator. Results have shown a good agreement with the internal measuring system of the generator but the $\mathrm{kVp}$ meters have shown both good and bad results depending the exposure time, the current and the positioning.
\end{abstract}

\section{INTRODUCTION}

High voltage invasive reference measuring system, for the calibration of pulsed X-ray high voltage tube in radiology applications, has been recently developed within the frame of the EMPIR project UHV 15RNM02 [1] . This reference system has been developed in LNE (National Metrology Institute in France) FFII (National Metrology Institute in Spain), GEMS Buc (General Electric Medical Systems France Buc) and CEA Sacly (Commissariat à l'Energie Atomique et aux Energies Alternatives).

The reference system is composed of two compensated resistive high voltage dividers; the first is for anode voltage up to $75 \mathrm{kV}$ and the second is for cathode voltage down to $-75 \mathrm{kV}$, the maximum voltage from anode to cathode is equal to $150 \mathrm{kV}$ Peak. The standardized quantity used in radiology PPV (Practical Peak Voltage [4]) and its traceability have been already published in [2]. The procedure used for the characterisation of the reference system has been also discussed in [3]. The obtained uncertainties are $0,4 \%$ for PPV (or peak voltage) and $1 \%$ to $2 \%$ for time parameters (rise time and time exposure). They are validated for every waveform with a rise time from $1 \mu$ s to $500 \mu$ s and a duration from $50 \mu$ s to few seconds.

Non-invasive instrument ( $\mathrm{kVp}$ meters) are widely used in radiology for qualification and quality control of X-ray pulses [5]. They determine with a simple procedure kilovolts applied to the tube. In order to characterize accuracy of $\mathrm{kVp}$ meters, a test bench has been developed in GEMS. The comparison is done with the invasive reference system.
The advantages of $\mathrm{kVp}$ meters are that they do not modify the $\mathrm{X}$-ray equipment configuration - equipment behavior remains unchanged. In comparison, external reference high-voltage dividers, physically connected to the X-ray equipment modify the equipment behaviour. Reference divider and connection cable to the equipment bring additional high-voltage capacitance, which slows down voltage rise time and fall time, and filters the ripple. Because rise time, fall time and ripple contribute to PPV calculation, a "minimally-invasive" configuration has been used for comparison between $\mathrm{kVp}$-meter measure and reference divider PPV.

\section{MINIMALLY-INVASIVE TEST BENCH}

To perform short X-ray exposures with fast rise time and fall time, the X-ray source used comes by-design with a low capacitance: $330 \mathrm{pF}$ total, spread in high-voltage transformer $210 \mathrm{pF}, \mathrm{X}$-ray tube and high-voltage cable $120 \mathrm{pF}$ (HV cable is very short, $70 \mathrm{~cm}$ only). The source is unipolar, anode grounded, operating down to $-140 \mathrm{kVp}$. In the following experiments, exposures are limited to $-75 \mathrm{kVp}$.

The entire source is placed in a large faraday cage, as shown in figure 1 , to allow required free air volume around the reference divider. Its connection to the source is provided between the X-ray tube and the HV generator. $\mathrm{HV}$ connector has been modified to receive a long open port receiving a copper wire up to the reference divider. This port is not shielded, resulting in around $1 \mathrm{pF}$ additional capacitance. Insulation is provided by plastic parts filed with high-voltage oil - Figures $2 \& 3$.

* Corresponding author: mohamed.agazar@lne.fr 


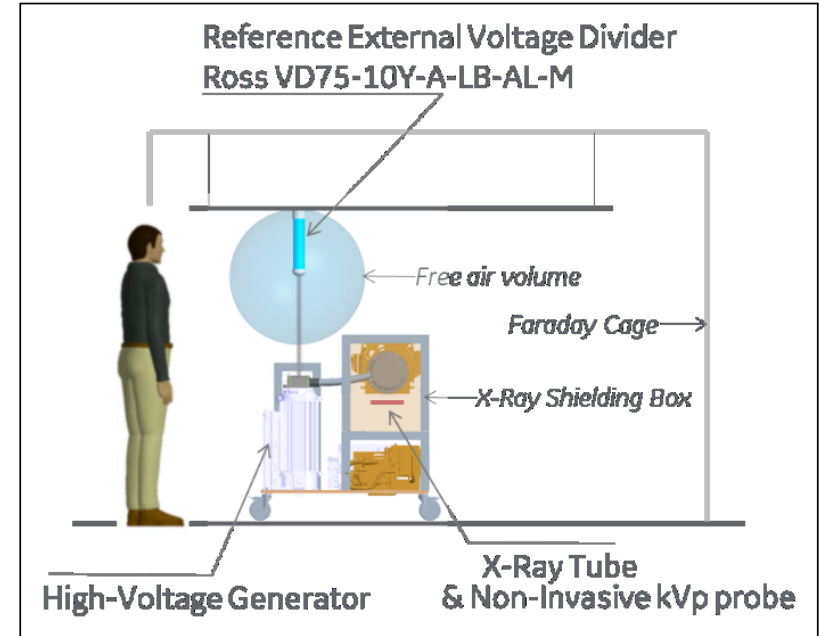

Fig. 1. Conceptual views of minimally invasive connection between high-voltage source and reference divider.

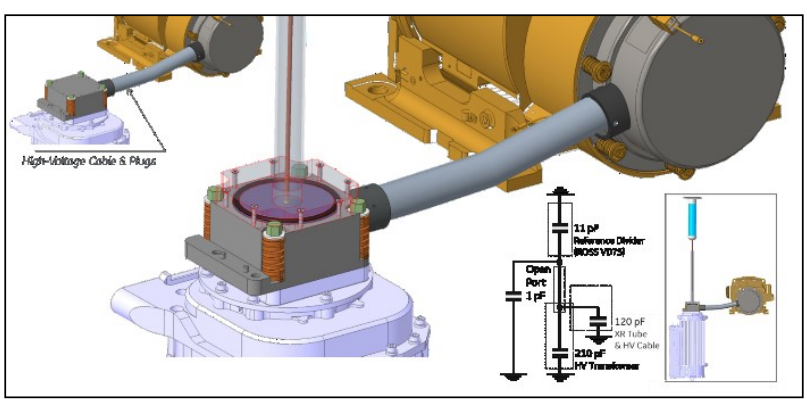

Fig. 2. Minimally invasive system configuration. Top left image shows the high-voltage cable standard configuration (before modification)

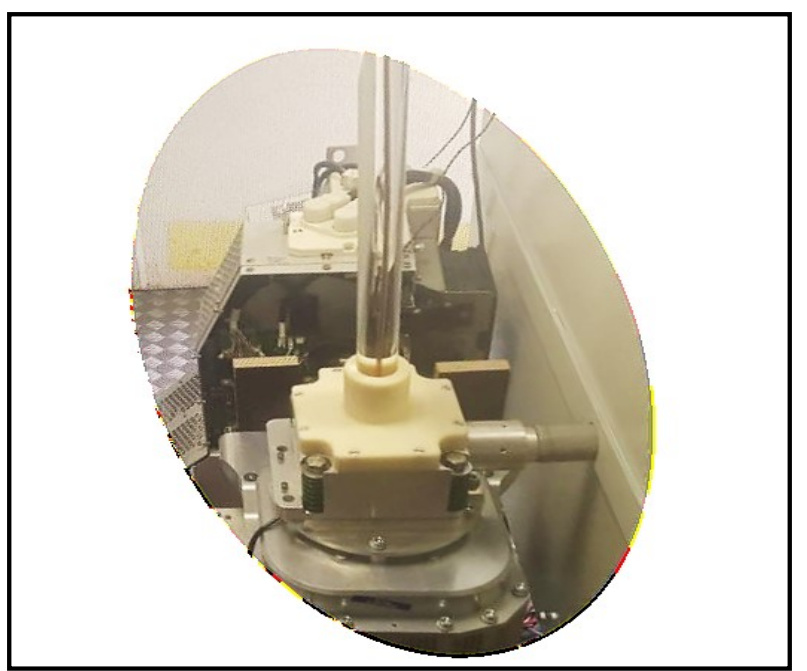

Fig. 3. Actual realization of the connection between highvoltage source and reference divider. (Connection add around $1 \mathrm{pF}$ capacitance, compare to total X-ray source $330 \mathrm{pF}$ and reference divider $11 \mathrm{pF}$ ).

The x-ray tube is surrounded by a lead box specially designed to respect very short high-voltage cable assembly configuration while totally shielding X-ray radiations. A door is provided to place the $\mathrm{kVp}$-meter in the X-ray beam. Tube heat-exchanger is located out of the shielding box.

the bottom shielding plate (RaySafe-X2 in the front, RTIPiranha in the back).
The principle of the measuring set is described in figure 4 . It includes the reference divider associated with its 12 bits digitizer and its reference software. Exposure is trigged through X-ray generator control digital interface, tube voltage and $\mathrm{kVp}$-meter data are acquired simultaneously.

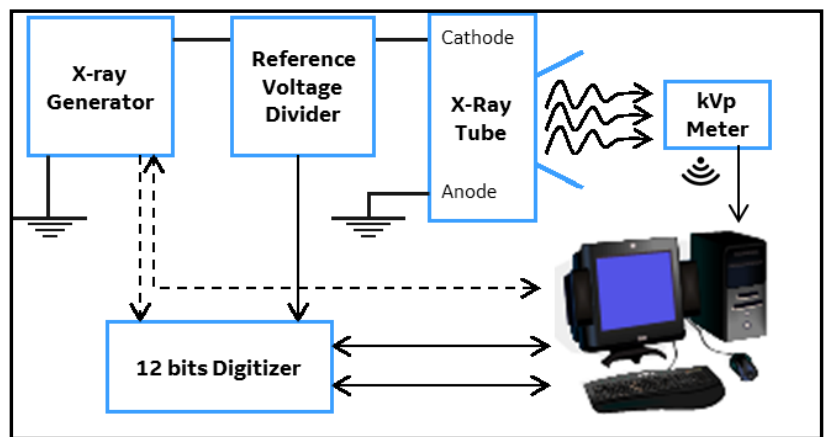

Fig. 4. $\mathrm{kVp}$ comparative measurement setup.

\section{RESULTS OF CHARACTERIZATION}

\subsection{Comparison Measurements}

In a first measurement session, $\mathrm{kVp}$-meter outputs are compared to reference voltage divider and generator analog output "base" value reported by the digitizer. Base value defined as "the value of most probable lower state" of the signal (excluding rise and fall sections). An additional reference divider from North Star and generator $\mathrm{kV}$ digital output have been included in the comparison. Six exposures are recorded: $10 \mathrm{~ms}, 100 \mathrm{~ms}$ and $1000 \mathrm{~ms}$ at $70 \mathrm{kV}-100 \mathrm{~mA}$, and $10 \mathrm{~ms}, 100 \mathrm{~ms}$, $1000 \mathrm{~ms}$ at $75 \mathrm{kV}-100 \mathrm{~mA}$. Results of measurements at $70 \mathrm{kV}$ are reported in figure 5 , they show around $2 \%$ difference between reference divider base value and RTI Black Piranha (old generation $\mathrm{kVp}$-meter), around $0.5 \%$ between reference divider base value and RaySafe X2 (new generation $\mathrm{kVp}$-meter). Invasive system from North Star and from GEMS internal measuring system (generator Analog and Digital outputs) show an error of about $0,5 \%$.

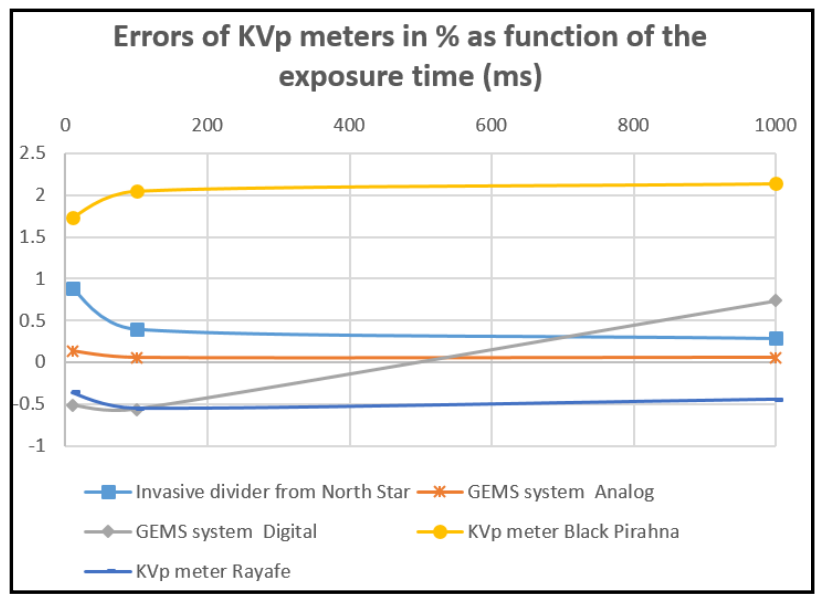

Fig. 5. Comparison results of few $\mathrm{kVp}$ meters for exposure time from $10 \mathrm{~ms}$ to $1000 \mathrm{~ms}$ at $70 \mathrm{kV}$. 


\subsection{Dynamic Measurements}

Dynamic records has been performed by the $\mathrm{kVp}$ meter which has shown the lowest errors (Raysafe X2). The figure 6 , highlight response time limitation of the $\mathrm{kVp}$ meter measure chain. Intended use of $\mathrm{kV}$-meters is actually non-invasive PPV measurement, not real-time voltage acquisition. The results show about $3 \mathrm{~ms}$ response delay versus the reference invasive standard. It could be concluded that the non-invasive instrument does not allow transient voltage recordings.

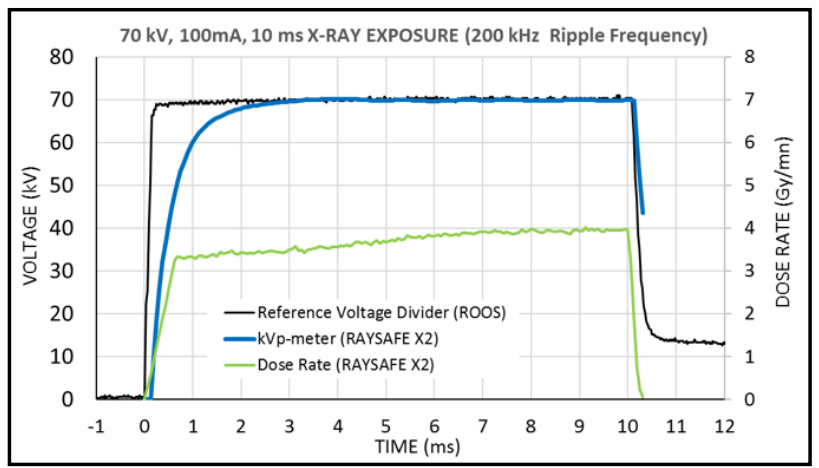

Fig. 6. Comparative $\mathrm{kVp}$ dynamic record for a $10 \mathrm{~ms}$ exposure at $70 \mathrm{kV}-100 \mathrm{~mA}$

\section{3 mA sensitivity - $100 \mathrm{~ms}$ exposure}

In this section, the objective is to compare $\mathrm{kVp}$-Meter measure and PPV value computed from reference divider voltage records, for different exposure parameters. RaySafe X2 kVp meter has been compared to the calibrated reference divider. Exposure voltage is set at 75 $\mathrm{kV}$, exposure duration is set at $100 \mathrm{~ms}$ and tube current $(\mathrm{mA})$ varies from $10 \mathrm{~mA}$ to $590 \mathrm{~mA}$ (11 experimental records at $10 \mathrm{~mA}, 100 \mathrm{~mA}, 200 \mathrm{~mA}, 250 \mathrm{~mA}, 300 \mathrm{~mA}$, $350 \mathrm{~mA}, 400 \mathrm{~mA}, 450 \mathrm{~mA}, 500 \mathrm{~mA}, 550 \mathrm{~mA}$ and 590 $\mathrm{mA}$ ). Around $600 \mathrm{~mA}$ the $\mathrm{kVp}$-meter is saturating in current experimentation conditions $(200 \mathrm{~mm}$ source to $\mathrm{kVp}$-meter distance).

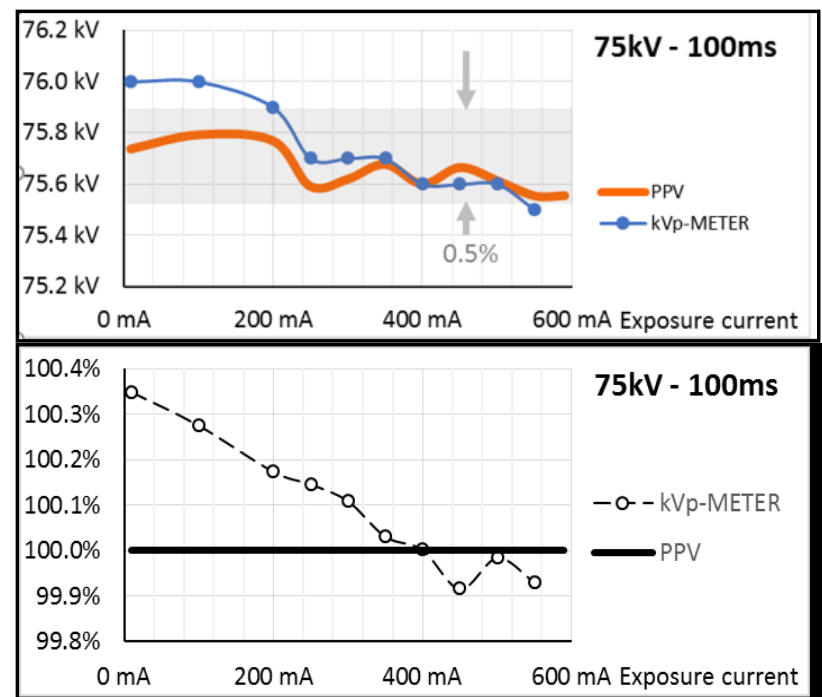

Fig. 7a \& 7b. Reference PPV compared with PPV measured by the $\mathrm{kVp}$ meter.
For $100 \mathrm{~ms}$ exposure, $\mathrm{kVp}$-meter calibration is better at high $\mathrm{mA}(0.1 \%$ in $300-600 \mathrm{~mA}$ range), lower $\mathrm{mA} \mathrm{kVp}$ meter values shifting up to $0.4 \%$ (worse case) compare to $\mathrm{PPV}$ values from reference divider (figure $7 \mathrm{a} \& 7 \mathrm{~b}$ ).

Additionally, calculated PPV is compared to $\mathrm{kV}$ average values at $75 \%$ of max voltage, $\mathrm{kV}$ average values at $90 \%$ of max voltage, and "base" value (i.e. most probable lower state) - Figure $7 \mathrm{c}$. Base value is shifted by $0.1 \%$ to $0.3 \%$ without correlation with $\mathrm{mA}$. For long exposures $(100 \mathrm{~ms})$ Average values stays within $+/-0.1 \%$ of PPV value. Difference can be attributed to $\mathrm{mA}$ effect on fall time (fall time is longer at low $\mathrm{mA}$ due to less discharge current) and to $\mathrm{mA}$ effect on voltage ripple, ripple being lower at low $\mathrm{mA}(2.5 \%$ ripple at $10 \mathrm{~mA}$ versus $6 \%$ at $600 \mathrm{~mA})$.

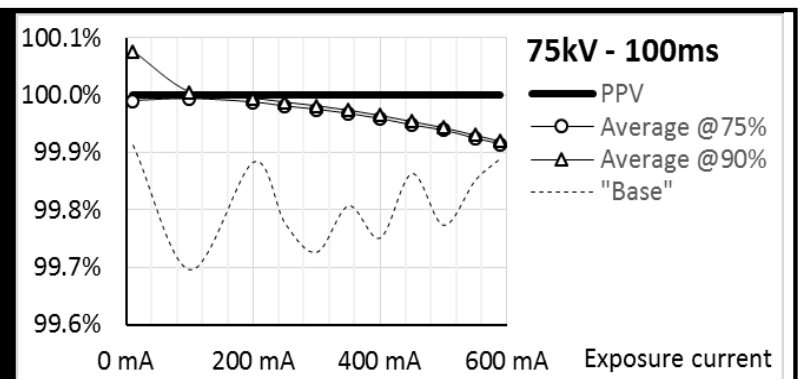

Fig. 7c. Reference PPV compared with $\mathrm{kV}$ average values and digitizer "base" value.

\subsection{Exposure duration sensitivity}

Exposure voltage has been set at $75 \mathrm{kV}$, exposure duration and tube current $(\mathrm{mA})$ vary respectively from $100 \mathrm{~ms}$ to $0.7 \mathrm{~ms}$ and from $10 \mathrm{~mA}$ to $550 \mathrm{~mA}$ (18 experimental records, 6 exposure duration stations, $100 \mathrm{~ms}, 10 \mathrm{~ms}, 5$ $\mathrm{ms}, 2 \mathrm{~ms}, 1 \mathrm{~ms}, 0.7 \mathrm{~ms}$, and 3 tube current stations, 10 $\mathrm{mA}, 300 \mathrm{~mA}, 550 \mathrm{~mA})$.

Experimental results highlight $\mathrm{kVp}$-meter sensitivity to dose (figure 8a). In current experiment conditions $\mathrm{kVp}$ meter did not operate when jointly $\mathrm{mA}$ and exposure durations are high, and when jointly $\mathrm{mA}$ and exposure durations are low. Comparative analysis is here possible for $300 \mathrm{~mA}$ stations only.

The reference PPV calculated value as a function of exposure duration and $\mathrm{mA}$. Curve inflection toward low exposure durations can be attributed to contribution of rise and fall time in PPV calculation (rise and fall time getting relatively higher when exposure duration reduces). The drop is accentuated at very low $\mathrm{mA}$ as fall time become longer due to low discharge current.

The results show a good correlation $(<0.3 \%)$ between $\mathrm{kVp}$-meter and PPV values for $300 \mathrm{~mA}$ exposures for the different exposure duration stations. 


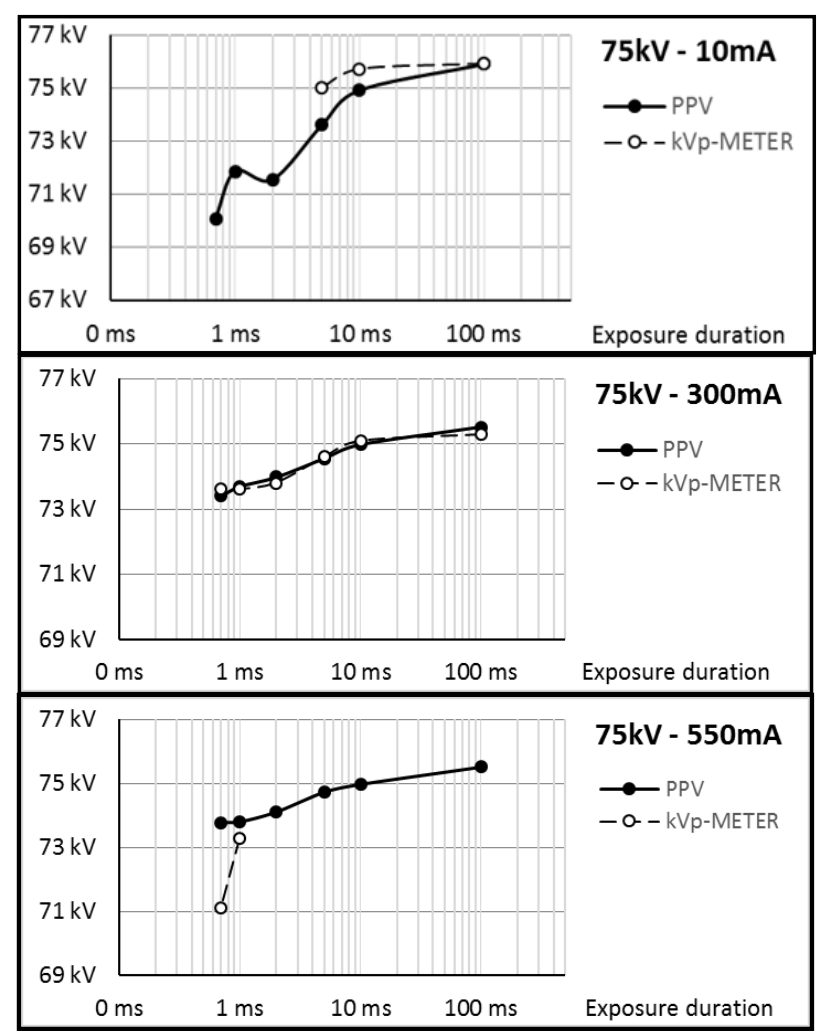

Fig. 8a. Exposure duration sensitivity performed at $75 \mathrm{kV}$ and a current from $10 \mathrm{~mA}$ to $550 \mathrm{~mA}$.

Additional comparison between PPV and $\mathrm{kV}$ average values shows up to $2 \%$ drift below $5 \mathrm{~ms}$ exposure duration (figure $8 \mathrm{~b}$ ). Average $\mathrm{kV}$ at $75 \%$, which is often used in X-ray exposure specifications, cannot be considered as a "fair estimation" of PPV for short exposures.

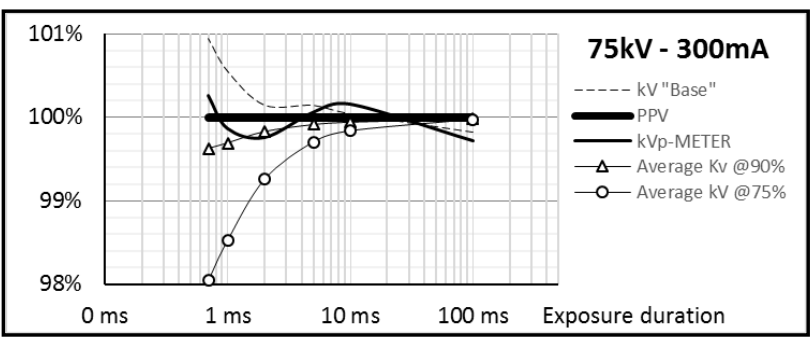

Fig. 8b. Exposure duration sensitivity performed at $75 \mathrm{kV}$ $300 \mathrm{~mA}$.

\subsection{Positioning of the $\mathrm{kVp}$-meters}

$\mathrm{kVp}$ meters positioning in confined environment is very important. $\mathrm{kVp}$ meter is significantly shifted from the central position under the $\mathrm{X}$-ray source. The 10 positions of $\mathrm{kVp}$-meter (two vertical shifting high and low, each one has 5 positions as described in figure 9) relative to lead-box, X-ray source and expected X-ray beam location.

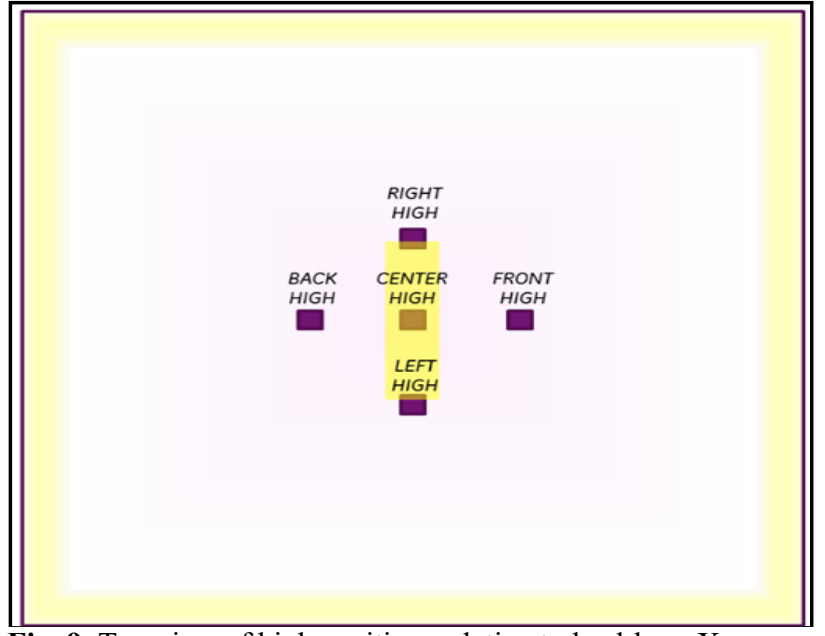

Fig. 9. Top view of high position, relative to lead-box, X-ray source and expected X-ray beam.

$\mathrm{kVp}$-meter values are compared with PPV values. Results are summarized in tables 1 and 2.

Table 1: kVp-meter 5 locations - position HIGH

\begin{tabular}{|c|c|c|c|c|c|c|}
\hline \multicolumn{3}{|c|}{ EXPOSURE PARAMETERS } & $\begin{array}{c}\text { REF. DIVIDER } \\
\text { (NSS }\end{array}$ & \multicolumn{3}{|c|}{ Non-Invasive Raysafe (X2) } \\
\hline VOLTAGE & CURRENT & DURATION & $\operatorname{PPV}(\mathrm{kV})$ & POSITION & kVp-METER & $(\mathrm{kV})$ \\
\hline $75 \mathrm{kV}$ & $10 \mathrm{~mA}$ & $100 \mathrm{~ms}$ & 75.693 & \multirow{3}{*}{$\begin{array}{c}\text { CENTER } \\
\text { HIGH }\end{array}$} & 75.900 & $0.27 \%$ \\
\hline $75 \mathrm{kV}$ & $100 \mathrm{~mA}$ & $100 \mathrm{~ms}$ & 75.675 & & 75.600 & $-0.10^{\circ}$ \\
\hline $75 \mathrm{kV}$ & $500 \mathrm{~mA}$ & $100 \mathrm{~ms}$ & 75.466 & & No feedback & NA \\
\hline $75 \mathrm{kV}$ & $10 \mathrm{~mA}$ & $100 \mathrm{~ms}$ & 75.641 & \multirow{3}{*}{$\begin{array}{c}\text { FRONT } \\
\text { HIGH }\end{array}$} & No feedback & NA \\
\hline $75 \mathrm{kV}$ & $100 \mathrm{~mA}$ & $100 \mathrm{~ms}$ & 75.858 & & No feedback & NA \\
\hline $75 \mathrm{kV}$ & $500 \mathrm{~mA}$ & $100 \mathrm{~ms}$ & 75.567 & & 53.600 & $-29 \%$ \\
\hline $75 \mathrm{kV}$ & $10 \mathrm{~mA}$ & $100 \mathrm{~ms}$ & 75.742 & \multirow{3}{*}{$\begin{array}{l}\text { BACK } \\
\text { HIGH }\end{array}$} & No feedback & NA \\
\hline $75 \mathrm{kV}$ & $100 \mathrm{~mA}$ & $100 \mathrm{~ms}$ & 75.866 & & No feedback & NA \\
\hline $75 \mathrm{kV}$ & $500 \mathrm{~mA}$ & $100 \mathrm{~ms}$ & 75.478 & & No feedback & NA \\
\hline $75 \mathrm{kV}$ & $10 \mathrm{~mA}$ & $100 \mathrm{~ms}$ & 75.929 & \multirow{3}{*}{$\begin{array}{l}\text { RIGHT } \\
\text { HIGH }\end{array}$} & No feedback & NA \\
\hline $75 \mathrm{kV}$ & $100 \mathrm{~mA}$ & $100 \mathrm{~ms}$ & 75.911 & & No feedback & NA \\
\hline $75 \mathrm{kV}$ & $500 \mathrm{~mA}$ & $100 \mathrm{~ms}$ & 75.564 & & 49.300 & $-35 \%$ \\
\hline $75 \mathrm{kV}$ & $10 \mathrm{~mA}$ & $100 \mathrm{~ms}$ & 75.980 & \multirow{3}{*}{$\begin{array}{l}\text { LEFT } \\
\text { HIGH }\end{array}$} & No feedback & NA \\
\hline $75 \mathrm{kV}$ & $100 \mathrm{~mA}$ & $100 \mathrm{~ms}$ & 75.721 & & No feedback & NA \\
\hline $75 \mathrm{kV}$ & $500 \mathrm{~mA}$ & $100 \mathrm{~ms}$ & 75.561 & & 53.000 & $-30 \%$ \\
\hline
\end{tabular}

Table 2: kVp-meter 5 locations - position LOW

\begin{tabular}{|c|c|c|c|c|c|c|}
\hline \multicolumn{3}{|c|}{ EXPOSURE PARAMETERS } & \multirow{2}{*}{$\begin{array}{c}\begin{array}{c}\text { REF. DIVIDER } \\
\text { ROSS VD75 (N¹) }\end{array} \\
\text { PPV (kV) }\end{array}$} & \multicolumn{3}{|c|}{ Non-Invasive Raysafe (X2) } \\
\hline VOLTAGE & CURRENT & DURATION & & POSITION & kVp-METER & (kV) \\
\hline $75 \mathrm{kV}$ & $10 \mathrm{~mA}$ & $100 \mathrm{~ms}$ & 75.675 & \multirow{3}{*}{$\begin{array}{l}\text { CENTER } \\
\text { LOW }\end{array}$} & 76.000 & $0.43 \%$ \\
\hline $75 \mathrm{kV}$ & $100 \mathrm{~mA}$ & $100 \mathrm{~ms}$ & 75.745 & & 76.100 & $0.47 \%$ \\
\hline $75 \mathrm{kV}$ & $500 \mathrm{~mA}$ & $100 \mathrm{~ms}$ & 75.586 & & 75.700 & \begin{tabular}{|l|}
$\mathrm{NA}$ \\
\end{tabular} \\
\hline $75 \mathrm{kV}$ & $10 \mathrm{~mA}$ & $100 \mathrm{~ms}$ & 75.820 & \multirow{3}{*}{$\begin{array}{l}\text { FRONT } \\
\text { LOW }\end{array}$} & No feedback & NA \\
\hline $75 \mathrm{kV}$ & $100 \mathrm{~mA}$ & $100 \mathrm{~ms}$ & 75.788 & & 51.400 & NA \\
\hline $75 \mathrm{kV}$ & $500 \mathrm{~mA}$ & $100 \mathrm{~ms}$ & 75.694 & & 51.600 & $-32 \%$ \\
\hline $75 \mathrm{kV}$ & $10 \mathrm{~mA}$ & $100 \mathrm{~ms}$ & 75.821 & \multirow{3}{*}{$\begin{array}{l}\text { BACK } \\
\text { LOW }\end{array}$} & No feedback & NA \\
\hline $75 \mathrm{kV}$ & $100 \mathrm{~mA}$ & $100 \mathrm{~ms}$ & 75.800 & & No feedback & NA \\
\hline $75 \mathrm{kV}$ & $500 \mathrm{~mA}$ & $100 \mathrm{~ms}$ & 75.677 & & 52.200 & NA \\
\hline $75 \mathrm{kV}$ & $10 \mathrm{~mA}$ & $100 \mathrm{~ms}$ & 75.870 & \multirow{3}{*}{$\begin{array}{l}\text { RIGHT } \\
\text { LOW }\end{array}$} & No feedback & $\mathrm{NA}$ \\
\hline $75 \mathrm{kV}$ & $100 \mathrm{~mA}$ & $100 \mathrm{~ms}$ & 75.838 & & 60.900 & NA \\
\hline $75 \mathrm{kV}$ & $500 \mathrm{~mA}$ & $100 \mathrm{~ms}$ & 75.542 & & 60.600 & $-20 \%$ \\
\hline $75 \mathrm{kV}$ & $10 \mathrm{~mA}$ & $100 \mathrm{~ms}$ & 75.785 & \multirow{3}{*}{$\begin{array}{l}\text { LEFT } \\
\text { LOW }\end{array}$} & 66.600 & NA \\
\hline $75 \mathrm{kV}$ & $100 \mathrm{~mA}$ & $100 \mathrm{~ms}$ & 75.757 & & 66.600 & NA \\
\hline $75 \mathrm{kV}$ & $500 \mathrm{~mA}$ & $100 \mathrm{~ms}$ & 75.694 & & 66.600 & $-12 \%$ \\
\hline
\end{tabular}

Without surprise, only central positions give a good correlation with PPV reference with a deviation of about $0.6 \%$ between High and Low positions. Also, when located too close to the source $(\sim 20 \mathrm{~cm}), \mathrm{kVp}$-meter saturates at high mA $(550 \mathrm{~mA}, 75 \mathrm{kV}, 100 \mathrm{~ms})$.

In confined environment, when significantly shifted from central position $\mathrm{kVp}$-meter sometimes reports misleading values (mainly at high $\mathrm{mA}$ ), underestimating PPV by around $30 \%$. 


\subsection{Other influence quantities}

Other influence quantities have not yet been studied Temperature and humidity, amplitude and frequency of ripples, radiofrequencies disturbances and electrical field. This study has been performed in real conditions of use. The temperature was varying from $20{ }^{\circ} \mathrm{C}$ to $26{ }^{\circ} \mathrm{C}$ The amplitude of ripples was varying from $2 \%$ to $6 \%$ in 100 $\mathrm{kHz}$ to $300 \mathrm{kHz}$ frequency range. Radio frequencies and disturbances have been also shown and acquired by the reference divider, they include also several spikes and overshoots (figure 10).

The $\mathrm{kVp}$ meters errors obtained in this study could also due to these influence quantities.

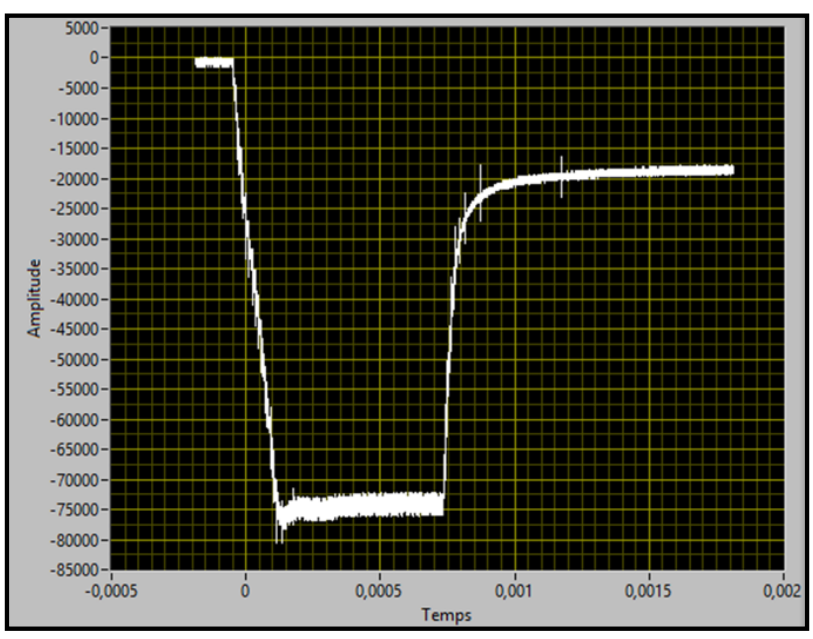

Fig 10. Reference divider voltage record for $75 \mathrm{kV}, 550 \mathrm{~mA}, 0.7$ $\mathrm{ms}$ exposure, $150 \mu$ s rise time. Overshoot and peaks are visible at the end of $\mathrm{kV}$ rise (located bottom left on the picture).

\section{RECOMMENDED LIMITS OF THE USE OF KVP METERS.}

Approaching kVp-meter reading capability limits, significant divergences with reference PPV have been observed - at high $\mathrm{mA}$ short exposure duration before saturation, and at low $\mathrm{mA}$ short exposure before loss of reading capability. Limits may vary between manufacturers and between technologies. PPV calibration based on reference divider measurements should allow to better define usage limits without being too much restrictive. $\mathrm{kVp}$ meters must be calibrated by comparison to an invasive system to check their accuracy within the condition of use such the exposure time, rise time, fall time, current, ripples and level of voltage. Theses parameters could affect the accuracy of $\mathrm{kVp}$ meters.

Only central positions give a good correlation with PPV reference. Also, when located too close to the source $(\sim 20$ $\mathrm{cm}), \mathrm{kVp}$-meter saturates at high $\mathrm{mA}(550 \mathrm{~mA}, 75 \mathrm{kV}$, $100 \mathrm{~ms}$ ). In confined environment, when significantly shifted from central position $\mathrm{kVp}$-meter sometimes reports misleading values (mainly at high $\mathrm{mA}$ ), underestimating PPV by around 30\%. Calibration of Xray tube must be performed with central position in the front of the voltage tube. Also distance range between central position and X-ray source must be specified according to exposure parameters $(\mathrm{kV}, \mathrm{mA})$ for each $\mathrm{kVp}$ meters.

Dynamic records highlight response time limitation of the $\mathrm{kVp}$-meter measure chain. Intended use of $\mathrm{kV}$-meters is actually non-invasive PPV measurement, they should not be used for real-time voltage acquisition, until new technologies bring them this capability.

The characterisation of $\mathrm{kVp}$ meters, before their use as standard for the qualification of X-ray tubes, is necessary to avoid inappropriate results. It could be performed by comparison to an invasive standard in the real condition of use.

\section{CONCLUSION}

A test bench has been developed to check the accuracy and the limits for the use of $\mathrm{kVp}$ meters. The measurements have been performed by comparison to a reference invasive system. For long X-ray exposure duration (above $10 \mathrm{~ms}$ ), errors between $\mathrm{kVp}$-meters and reference voltage "base" value were found within $2 \%$. Considering new technology $\mathrm{kVp}$-meter and reference PPV value (computed from reference voltage record), errors are found within $0.5 \%$ over a large range of $\mathrm{mA}$ and down to short exposure duration below $1 \mathrm{~ms}$, provided $\mathrm{kVp}$-meter is used in its beam intensity range (mAs). $\mathrm{kVp}$ meters have shown inappropriate results depending on beam intensity (mAs) and $\mathrm{kVp}$ meter probe positioning. Errors could sometimes reach $30 \%$ depending how $\mathrm{kVp}$ meters are used. Calibration and verification of the $\mathrm{kVp}$ meter to check their accuracy in the same condition of use by comparison to a calibrated invasive standard is essential to avoid undesirable errors.

\section{ACKNOWLEDGEMENT}

The work reported here has received support from the EMPIR programme co-financed by the Participating States and from the European Union's Horizon 2020 research and innovation programme.

\section{REFERENCES}

1. Website of the project "Techniques for ultra-high voltage and very fast transients" https://www.vtt.fi/sites/UHV.

2. M.Agazar, D. Fortune, H. Saadeddine and J. Plagnard, "Reference system for the Practical Peak Voltage calibration in Radiology and diagnostic applications", Proceedings of Conference on Precision Electromagnetics Measurements (CPEM 2018), July, 8-13, 2018, Paris, France, https://doi.org/10.5281/zenodo.1471188

3. M. Agazar, D. Fortune, Hanane Saadeddine, F. Garnacho, J. Rovira "Characterisation of high voltage dividers for X-ray measurements" $21 \mathrm{st}$ International Symposium on High Voltage 
Engineering, (ISH 2019), 26-30 August 2019, Budapest, Hungary, https://doi.org/10.5281/zenodo.3243494

4. IEC 61676 "Medical electrical equipment Dosimetric instruments used for non-invasive measurement of X-ray tube voltage in diagnostic radiology" 2009. Annexe B.

5. IEC 60601-1-3 "Medical electrical equipment -Part 1-3: General requirements for basic safety and essential performance -Collateral Standard: Radiation protection in diagnostic X-ray equipment" 2013-04. 